\title{
Posverdad. La nueva guerra contra la verdad y cómo combatirla. Mattew d'Ancona, Alianza Editorial, 2019
}

Sebastià Vives ${ }^{1}$

El autor nos introduce en el debate epistemológico que gira entorno a cómo conceptualizar alguno de los fenómenos sociales actuales que se ha concretado en hechos tales como la llegada al poder de Trump, o el denominado Brexit por el que se inicia el proceso de desvinculación entre Gran Bretaña y la UE. Pese al alto componente ideológico que rige en ellos, el autor deja claro desde el principio que su intención no es en ningún caso ideológica sino de conocimiento y, por tanto, relativa al saber, a su naturaleza y su transmisión.

$\mathrm{Su}$ tesis principal, sobre la conexión entre verdad y comunicación política, es que recientemente y progresivamente ha ido decayendo el valor de la verdad como divisa de la sociedad, y esto ha dado como resultado un pernicioso desarrollo del relativismo.

El texto pone el foco en el trasfondo político y filosófico de los hechos sociales que revisa, pero también emite diagnósticos y valoraciones. En este sentido refiere, por ejemplo, al pensamiento de George Orwell y su obra, que alertaba sobre el peligro que puede suponer que la historia sea contada y reproducida, no desde los ejes

${ }^{1}$ Grado de Sociología. Universidad de Barcelona

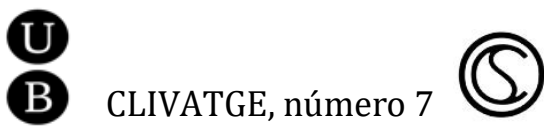


del conocimiento, sino desde la construcción de mentiras. A renglón seguido, valora lo que ahora está ocurriendo como un peligro que no radica sólo en que la historia puede ser contada falsamente, sino que se está abonando la idea de que la historia no puede ni escribirse ni contarse, y aún menos puede ser pensada de una forma veraz, es decir, el mal mayor peligro radica en el desprestigio del oficio de historiador, junto con el desprestigio de la Historia como disciplina, que se está produciendo. Esta es la idea que se extiende y con la que se nos inhabilita para combatir cualquier clase de mentira que pueda prosperar en el presente. El autor propone una etiqueta para clasificar el conjunto de este proceso actual con la que, desde el mismo título, sentencia: estamos en la era de la posverdad y su inicio definitivo tiene lugar en el año 2016.

A lo largo del libro se examina cómo se gesta esta pérdida del valor de la verdad. Se refiere principalmente a hechos y declaraciones relacionados con altos dirigentes políticos de Estados Unidos y del Reino Unido. Los numerosos ejemplos que se desmenuzan a lo largo de este pequeño libro ayudan a entender las consecuencias que puede llegar a tener el desplazamiento de la verdad como valor fundamental en las relaciones políticas y sociales. Hacia el final de la obra, el autor examina también las bases filosóficas del "relativismo posmoderno", y propone, además, algunas de las medidas para llevar a cabo el combate contra la mentira. El objetivo es tratar de contribuir a que retorne la verdad como posición central de la dinámica social, es decir, tratar de recuperar lo que en la historia de la filosofía y en la ciencia occidental, según el autor, la verdad siempre había representado.

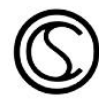


La racionalidad se ve amenazada por las emociones

Según un estudio de PolitiFact, un 69\% de las afirmaciones que Trump realizó durante su campaña (que ha mantenido después de ella) son esencialmente falsas ${ }^{2}$. Entonces, ¿por qué los ciudadanos decidieron votarle? Según el autor, la respuesta la vamos a encontrar en las claves que definen a esta era posverdad.

Una de las principales características que perfilan la era de la posverdad es la desconfianza en la honestidad y exactitud que guían los fines de la ciencia. Cuando la visión del presente se impregna de esta desconfianza, es fácil que los hechos objetivos puedan ser suplantados por una opinión pública que se alimenta de creencias personales y emociones, pero también al revés, cuando la vida social se rige fundamentalmente por opiniones y emociones, es fácil que crezca el descrédito y la desconfianza por la verdad que puede entrañar la ciencia.

Otra de las claves, formulada ahora también en forma de pregunta: ¿Cómo podemos establecer un compromiso legislativo razonado si la cultura política (entendida aquí como la opinión política y el discurso que emiten los medios) ha quedado desconectada de la base legislativa de la política? La era de la posverdad se caracteriza por no tener una realidad estable y verificable, tan solo existe una batalla interminable por definirla; es la

\footnotetext{
${ }^{2}$ https://www.politifact.com/truth-o-meter/lists/people/comparing-hillary-clintondonald-trump-truth-o-met/
}

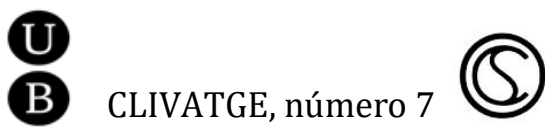


batalla entre interpretaciones, batalla que abre la puerta a la puesta en práctica de formulaciones populares y populistas en su peor sentido. En esto ha consistido la campaña exitosa de Trump: salió victorioso en las elecciones de 2015 y afirmó que había logrado la mayor victoria en votos electorales desde Ronald Reagan (sin embargo, el contraste de los hechos nos informa que en 2008 Obama había conseguido sesenta y un mil votos más); afirmó que los azulejos de una de sus casas habían sido confeccionados personalmente por Walt Disney, afirmación por la que fue tachado públicamente de falso y además ridículo, ante lo que no tuvo otra respuesta que "qué más da", que le daba igual.

El Brexit del Reino Unido ha estado regido por las mismas normas. La campaña por la permanencia en Europa resultó la perdedora en el Referéndum porque presentaba un hecho tras otro, y esto en la era de la posverdad no da resultado. Ahora más que nunca para ganar en las urnas hace falta conectar con la gente de forma emocional.

En la campaña a favor de la salida de la UE se hizo una referencia constante a la amenaza que representaba la fuerte inmigración, que quitaba a los autóctonos plazas escolares, empleo, atención sanitaria y viviendas. Pero nunca se dijo que la salida de la Unión Europea en ningún caso podía modificar las reglas más básicas de trato a la inmigración, ya que éstas provienen y son competencia de las Naciones Unidas.

El autor insiste en que, en la era de la posverdad, la racionalidad es amenazada por la sobreabundancia de estímulos y mensajes 
puramente emocionales, antes que por la mentira directa ya que, aunque aparezca y la podamos contabilizar de manera escandalosa, ésta no es la diferencia central de esta era si la comparamos con otras épocas. De hecho, la formulación de la mentira ha formado parte de la estrategia y de la actividad política desde siempre. Lo importante de la era de la posverdad es la búsqueda sistemática en el público de la respuesta emocional ante las mendacidades que formulan algunos políticos. Mentir forma parte de la norma de funcionamiento de las democracias actuales pero, si quien llega al poder normaliza la mentira, la disemina y la extiende entre la población y además queda impune por ello, este personaje y los mecanismos institucionales de los que se sirve pueden también definir lo que es verdad. Es decir, la mentira es más peligrosa cuando consigue contaminar y diluir la verdad. La verdad no sólo depende de los hechos en sí, sino de cómo se comunican, porque en el cómo se comunican radica el proceso de creación de segundas verdades, y éstas pueden llegar a usurpar el lugar que corresponde a los hechos en sí mismos.

En el campo de batalla de la era posverdad se accede bajo la premisa de que nada es verdad y todo es posible. En este sentido, Richard Sennet ya había alertado sobre el declive del hombre público cuando se produce una colonización de la esfera pública desde una esfera privada que se articula exclusivamente en una incansable búsqueda egoísta de "uno mismo" (de sus intereses, posiciones o identidad). Tal búsqueda personal contribuye a hacer imposible la gestión de la vida pública mediante el consenso y la política . Es desde aquí, tal y como se subraya en esta obra, desde

B CLIVATGE, número 7

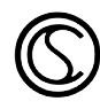


donde podemos entender la importancia que se ha dado contemporáneamente al psicoanálisis. Como terapia, su éxito social se debe en su eficacia al tratar a los pacientes en función de las neurosis personales, pero no desde la verdad o la mentira de su identidad. Es peligroso extender los objetivos de la terapia psicoanalítica más allá de lo que es su función y servirnos de ellos como guía de interpretación de los ejes predominantes de la cultura y de los valores contemporáneos, y esto es lo que se ha hecho en la era posverdad.

\section{Posverdad y desinformación}

La gente está harta de los expertos. Esta afirmación fue un recurso propagandístico predominante en la campaña VoteLeave, a favor de la salida de la Unión Europea. Lo curioso es que la persona que la dijo era uno de los intelectuales más importantes del partido conservador británico, el cual estaba completamente dividido entre personas a favor y en contra de la salida.

El desplome de la credibilidad y la confianza en el otro es también una clave social de la era posverdad. Si las sociedades dependen de un grado alto de honestidad para mantener el orden, nuestra sociedad actual ha caído en un círculo vicioso en el que nadie es capaz de confiar en nadie. Nunca te fíes de nadie. Los medios de comunicación han jugado un papel esencial en este auge de la desconfianza. Si en función de cómo se cuentan los hechos se puede crear segundas verdades ( $\mathrm{y}$ estas segundas pueden llegar a ser consideradas más importantes que estas primeras) los medios de

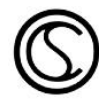


comunicación han contado los hechos simplificando a toda costa sus detalles y matices, hasta el punto de haber eliminado el rastro de los hechos objetivos, y así es como los medios se han convertido en los instrumentos centrales para la reproducción de la desconfianza. La difusión sistemática de falsedades forma parte de una coordinada ofensiva estratégica concebida para ocultar la verdad y confundir al público. Aquí está la diferencia que anteriormente, haciendo referencia a Orwell, comentábamos. Confundir al público significa hacer creer que no existe la posibilidad de alcanzar un consenso científico con el que ofrecer la descripción y explicación de un hecho y reconocerlo como objetivo.

Internet ha tenido mucho que ver con la metamorfosis a gran escala de los medios de comunicación. Los sistemas de información que predominaban en tiempos de producción fordista, rígida y semejante, han dejado de ser jerárquicos. La información se ha convertido en el bien más preciado del mundo y se han creado bancos de datos donde cada uno de nosotros depositamos algún tipo de información sobre nosotros. Big data es uno de los ejemplos actuales más importantes que ha sido utilizado en muchos casos para manipular mercados financieros y procesos políticos ${ }^{3}$.

${ }^{3}$ Robert Mercer, un empresario multimillonario estadounidense, donó grandes cantidades de dinero a la campaña de Trump y a la campaña a favor del Brexit. Las dos campañas utilizaron el banco de datos de CambridgeAnalytica, uno de los bancos de datos más importantes y influyentes en los procesos políticos contemporáneos del qual Mercer era presidente. 
En general, todo lo que ha posibilitado Internet de positivo se ha dado en paralelo a su uso más negativo: es una de las armas más importantes de la era de la posverdad porque facilita la simplificación a toda costa, con lo que se genera un menosprecio automático por cualquier cosa que represente complejidad y diversidad. Además, con el uso (al menos en parte) que estamos realizando de Internet ahora creamos nuestra propia realidad, con lo que podemos llegar a creer que la realidad exterior y objetiva ya no cuenta, y esto es otra forma de creer que a la realidad no la sustenta algún soporte de verdad objetiva.

\section{La paranoia de la conspiración}

Cuánto más desconfías en sistemas económicos y fiables, más propenso eres a elaborar o aceptar como válidas teorías conspirativas. El 50\% de la población hace suya, en un año cualquiera, al menos a una teoría conspirativa sobre algún tema. Por ejemplo, en 2007 en Inglaterra se inauguró el museo de la creación, en el mismo acto se repartían pegatinas con eslóganes que invitaban a "volver a recuperar los dinosaurios para el cristianismo", nueve años después los partidarios del Brexit querían "recuperar el control"4. La fe termina ganando porque apela al sentimiento y no a las pruebas. Las actitudes son más importantes que los hechos. Otro ejemplo tiene que ver con la campaña en contra de las vacunas realizada en Gran Bretaña, y las

${ }^{4}$ Take back the control era el eslogan de la campaña VoteLeave, a favor de la salida del Reino Unido de Europa.

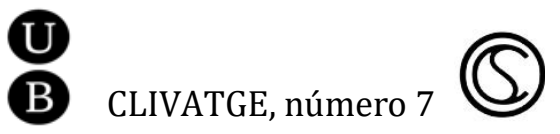


consecuencias negativas que ésta ha tenido en la apreciación de la ciencia de la salud.

Teoría de la posverdad, el posmodernismo

La posverdad como época histórica, al igual que otras etapas que han precedido, se encuentra influenciada por ideas diseñadas desde corrientes de pensamiento o teorías. Según el autor, es el cuerpo teórico y conceptual de la teoría posmoderna el acompañante fiel de la despolitización de las clases sociales de finales del siglo XX, y esta es la base teórica central de la era que estamos viviendo.

Uno de los puntos fuertes de la filosofía posmoderna es la idea de que la sociedad tiende cada vez más hacia el pluralismo y, por tanto, resulta lógico tratar de destacar la importancia de múltiples voces y contribuir a la negación del poder de una sola voz. Se insta así, desde la visión posmoderna, a deconstruir la totalidad de las instituciones y ámbitos sociales que pueden ejercen poder, ya que el poder no se transmite en estructuras localizables como las instituciones estrictamente políticas, sino en otras zonas como en lenguaje, el saber heredado, la historia o las palabras en sí. En definitiva, para el imaginario colectivo posmoderno la realidad objetiva no existe porque siempre ésta se cuenta siempre desde algún lado, desde algún interés, o desde alguna posición particular. Para la visión posmoderna esto es lo único que existe: mensajes sobre el mundo que se van recreando, transmitiendo y reproduciendo.
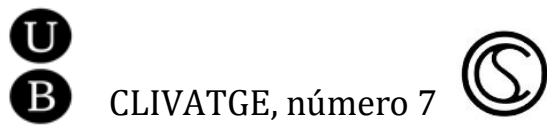
La posmodernidad se caracteriza por la creencia en la muerte de los metarrelatos provocada, como se ha dicho, por la destrucción de la historia. Ya no se puede entender el mundo desde una perspectiva históricamente sólida. No podemos salir de los significados que nos envían constantemente las tecnologías de la comunicación. Pero el autor aclara que no tiene ningún sentido afirmar también que los personajes de la era de la posverdad, como Trump, tienen contacto directo con las tesis posmodernas (de hecho, Trump afirma que no tiene tiempo para leer, o que quiere reconstruir el conservadurismo cristiano, mientras que los posmodernos quieren deconstruirlo).

El estudio de las ciencias sociales nos ha enseñado que tratar de conocer (o lo que es lo mismo, buscar la verdad) tiene un componente profundamente normativo. Por el contrario, el relativismo epistémico posmoderno se infiltra en la política para argumentar desde ella que ya no hace falta evaluar las evidencias, solo tenemos que elegir un bando entre los que se presentan como alternativas. En este sentido, tal y como se narra en el libro que presentamos, la era posverdad germina en medio de las visiones posmodernas que nos alejan completamente la posibilidad de alcanzar conocimiento, ciencia y la ética.

\section{El combate contra la posverdad}

El primer punto necesario a combatir en la era de la posverdad es la sobrecarga de información. La sobrecarga de información puede 
instrumentalizarse, si conviene, para ganar influencia política, social y cultural. Un sujeto que recibe constantemente estímulos informativos y los incorpora en su proceso de pensamiento, sin más esfuerzo, de forma completamente instrumental (sin activar la parte del cerebro que tanto esfuerzo requiere para elaborar la crítica, o para intentar cribar, comprobar y evaluar lo que nuestra mente recibe) está a merced de los intereses de quienes controlan la información.

El autor concluye que en los primeros años de escolarización los niños deberían aprender a seleccionar y discriminar lo que se ofrece desde el torrente de mensajes digitalizados. Y señala también que aunque puede que la presión pública haya conseguido que las grandes redes sociales empiecen a interesarse por la detección de noticias falsas en sus publicaciones, es necesario que la presión pública continúe hasta conseguir protegernos de exposición a la sobreinformación y a la fácil circulación de la mentira (porque los guerreros políticos van a seguir utilizando como armas las fake news, las que fácilmente reenviamos y damos por buenas).

Advierte y nos alerta sobre el error de creer que disponer de datos es disponer de la verdad, porque aunque lo primero contribuye a determinar lo segundo, no son la misma cosa. Y asevera que la verdad necesita también, hoy más que nunca, de un sistema emocional de transmisión que apele a la experiencia, a la memoria y a la esperanza. En este mundo no basta la argumentación intelectual, debemos superar el ingenuo pensamiento que cree que la batalla contra la posverdad se ganará solamente recurriendo a las técnicas de verificación rutinarias. Nos hemos vuelto indiferentes a las mentiras,

B CLIVATGE, número 7

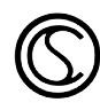


y más que nunca debemos reafirmar el valor de la verdad en el debate político, esto exige entender la importancia del nosotros en un mundo donde parece que ya no existe tal comprensión, donde la tensión entre la indiferencia y el compromiso parece que ya ha determinado un claro vencedor. Debemos apostar por la discusión racional pública como base para la articulación de sistemas que se caracterizan por su fiabilidad, afrontando la difícil tarea de combatir los tejidos argumentativos que perfilan la idea que predica que las ideologías son simples ficciones.

El conjunto del texto parece también invocar la verdad como "el" mito del que se sirve para activar en sus lectores la necesidad de su búsqueda. Ofrece una valoración positiva de la función de la historia como disciplina y nos recuerda la necesidad de orientarnos por valores y principios éticos. En definitiva, nos orienta a entender la verdad como premisa esencial para determinar la honestidad de una discusión democrática y racional que nos oriente en la comprensión de que existe "un nosotros" con fuerza suficiente para actuar como agente movilizador de cambios. 